\title{
Correction to: Clinical impact of hospital malnutrition
}

\author{
Concetta Finocchiaro ${ }^{1} \cdot$ Giovanni Fanni ${ }^{2} \cdot$ Simona Bo $^{2}$
}

Published online: 5 December 2018

(c) Società Italiana di Medicina Interna (SIMI) 2018

\section{Correction to: Internal and Emergency Medicine} https://doi.org/10.1007/s11739-018-1987-7

In the original publication, article was published with a wrong title as 'Risk, prevalence, and impact of hospital malnutrition in a Tertiary Care Referral University Hospital: a cross-sectional study' and also one of the references has been omitted in the reference list. The correct article title should be read as 'Clinical impact of hospital malnutrition'.

Also, the missing reference text is given below:

Rinninella E, Cintoni M, De Lorenzo A, Addolorato G, Vassallo G, Moroni R, Miggiano GAD, Gasbarrini A, Mele MC (2018) Risk, prevalence, and impact of hospital malnutrition in a Tertiary Care Referral University Hospital: a cross-sectional study. Intern Emerg Med 13(5):689-697. https://doi. org/10.1007/s11739-018-1884-0.

The original article can be found online at https://doi.org/10.1007/ s11739-018-1987-7.

Simona Bo

simona.bo@unito.it

1 Unit of Clinical Nutrition, Hospital of Turin, Città della Salute e della Scienza, Turin, Italy

2 Department of Medical Sciences, University of Turin, c.so AM Dogliotti 14, 10126 Turin, Italy 